\title{
Validation of Atmospheric Water Vapor Derived from Ship-Borne GPS Measurements in the Chinese Bohai Sea
}

\author{
Shi-Jie Fan ${ }^{1,2}$, Jian-Fei Zang ${ }^{1}$, Xiu-Ying Peng ${ }^{1,{ }^{*}}$, Su-Qin $\mathrm{Wu}^{2}$, Yan-Xiong Liu ${ }^{3}$, and Ke-Fei Zhang ${ }^{2}$ \\ ${ }^{1}$ School of Geosciences, China University of Petroleum, Qingdao, China \\ ${ }^{2}$ SPACE Research Centre, RMIT University, Melbourne, Australia \\ ${ }^{3}$ The First Institute of Oceanography, State Oceanic Administration, Qingdao, China
}

Received 25 April 2015, revised 4 October 2015, accepted 4 November 2015

\begin{abstract}
Atmospheric water vapor (AWV) was investigated for the first time in the Chinese Bohai Sea using a Global Positioning System (GPS) receiver aboard a lightweight (300-ton) ship. An experiment was conducted to retrieve the AWV using the state-of-the-art GPS precise point positioning (PPP) technique. The effects of atmospheric weighted mean temperature model and zenith wet delay constraint on GPS AWV estimates were discussed in the PPP estimation system. The GPS-derived precipitable water vapor (PWV) and slant-path water vapor (SWV) were assessed by comparing with those derived from the Fifth Generation NCAR/Penn State Mesoscale Model (MM5). The results showed the PWV and SWV differences between those derived from both GPS and MM5 are $1.5 \mathrm{~mm}$ root mean square (RMS) with a bias of 0.2 and $3.9 \mathrm{~mm}$ RMS with a bias of -0.7 $\mathrm{mm}$ respectively. These good agreements indicate that the GPS-derived AWV in dynamic environments has a comparable accuracy with that of the MM5 model. This suggests that high accuracy and high spatio-temporal resolution humidity fields can be obtained using GPS in the Chinese Bohai Sea, which offers significant potential for meteorological applications and climate studies in this region.
\end{abstract}

Key words: Global Positioning System, Precise point positioning, Precipitable water vapor, Slant-path water vapor, MM5 model, Bohai Sea Citation: Fan, S. J., J.F. Zang, X. Y. Peng, S. Q. Wu, Y.X. Liu, and K. F. Zhang, 2016: Validation of atmospheric water vapor derived from ship-borne GPS measurements in the Chinese Bohai Sea.Terr. Atmos. Ocean. Sci., 27, 213-220, doi: 10.3319/TAO.2015.11.04.01(A)

\section{INTRODUCTION}

Various space-based instruments such as satelliteborne microwave radiometers, Moderate-Resolution Imaging Spectroradiometer (MODIS) near-infrared channels, and ship-borne radiosondes released from operational weather ships are commonly used to sense oceanic atmospheric water vapor (AWV). However, the root mean square (RMS) error of AWV estimated from satellite-borne microwave radiometers (e.g., SSM/I) is greater than 4 - 5 mm (Jackson and Stephens 1995). The AWV obtained from MODIS is usually unavailable in cloudy areas and overestimates precipitable water vapor (PWV) against radiosondes and Global Positioning System (GPS) solutions, as shown in earlier studies (Gao and Kaufman 2003; Li et al. 2003). Radiosonde humidity data suffers from a dry bias during the daytime (Yoneyama et al. 2008) and their low spatial and temporal resolutions make it difficult to reveal fine varia-

\footnotetext{
* Corresponding author

E-mail:pengxy_92042@163.com
}

tions in humidity. Thus, deriving mesoscale moisture fields with high spatial and temporal resolutions is a challenge for quantitative precipitation forecasting within numerical weather prediction (NWP) models over sea regions.

Ground-based GPS meteorology has been proven to be a very effective method for AWV retrievals with high spatial and temporal resolutions in earlier studies (Bevis et al. 1992; Rohm et al. 2014; Yeh et al. 2014; Yuan et al. 2014). However, the oceanic AWV retrievals using a platform (ship or buoy) over sea regions have been confronted with some challenges, such as the dynamic nature of the platforms and the variability in the coordinate parameters for GPS receivers. Some preliminary results for PWV estimation using ship-borne or buoy-based GPS measurements have been demonstrated in the past decade. For example, one of the early researches conducted by (Chadwell and Bock 2001) using a moored buoy fitted with a GPS receiver off the California coast, showed the GPS-derived PWV (GPS-PWV) estimates agreed well with nearby land-based PWV estimates and radiosonde data. The GPS-PWV from 
ship-borne GPS measurements during cruises in the open sea was in good agreement with those from the radiosonde and the ship-based water vapor radiometer, as shown in earlier studies (Rocken et al. 2005; Fujita et al. 2008; Kealy et al. 2012). Boniface et al. (2012) compared the integrated water vapor over the Mediterranean Sea determined from ship-borne GPS with a NWP model and MODIS retrievals. These studies suggest that the accuracy of GPS-PWV for sea regions is comparable with that from the conventional means such as radiosonde and water vapor radiometer.

Due to the fact that PWV refers to the zenith direction, it cannot be directly used for 3D water vapor tomography over a region since the slant-path water vapor (SWV) information is required. However, limited studies on GPSderived SWV (GPS-SWV) over sea regions have been conducted so far. This is partly due to the difficulty in taking measurements aboard a moving platform and the lack of AWV reference information for GPS-SWV validation. Both GPS-PWV and GPS-SWV were investigated in this study using a lightweight (300-ton) ship in the Bohai Sea, which is the first of its kind attempt in China. These AWVs were estimated from the ship-borne GPS measurements with high dynamics using the precise point positioning (PPP) approach (Zumberge et al. 1997) and compared with the AWV from the Fifth Generation NCAR/Penn State Mesoscale Model (MM5) (Grell et al. 1994) for validation.

\section{EXPERIMENT DESCRIPTION}

An experiment was conducted in the Chinese Bohai Sea during November 22 - 24 (Day of Year: 326 - 328) 2010 by the First Institute of Oceanography, State Oceanic Administration of China. Figure 1a shows the sailing route of a lightweight (300-ton) experimental ship used as the platform for collecting both GPS and surface meteorological measurements. This ship is much smaller than the cruise ships used by Rocken et al. (2005) and Fujita et al. (2008) for conducting their experiments. The main consideration for using a small ship for our experiment is that it suffers sea-wave effects similar to that of buoys that would be deployed for future AWV retrievals over the sea regions. It is expected that the experimental results are representative of what can be obtained from buoys in the Bohai Sea. A Topcon geodetic choke ring antenna was installed on the ship deck facing the zenith (see Fig. 1b), and connected to a Topcon Net G3A dual-frequency GPS receiver. The GPS carrier phase and pseudo range observations were sampled at a 1-sec interval. A set of meteorological sensors mounted close to the GPS antenna was used to collect surface air temperature, pressure, and relative humidity at the same $1-\mathrm{sec}$ sampling rate (see Fig. 1b).

According to earlier studies (Memmo et al. 2005; Posada et al.2013), the PWV from the MM5 model was in good agreement with those measured by radiosondes, GPS, and ground-based microwave radiometers. Therefore, the MM5 model over the Bohai Sea, which has three nested grid domains using Lambert's conformal projection to obtain the highest resolution, was used to validate our ship-borne GPS AWV results. The initial fields were constructed from reanalysis data from the National Centers for Environmental Prediction (NCEP) with a $1.0^{\circ}$ resolution. The model used the planetary boundary layer parameterization, the KainFritsch 2 cumulus parameterization scheme (Kain 2004) and the cloud radiation scheme (Stephens 1984). The three domains had horizontal resolutions of 27,9 , and $3 \mathrm{~km}$. The vertical resolution had 35 levels up to a $20 \mathrm{~km}$ height divided by isobaric surfaces, which means that different points on the same isobaric layer may have different heights. The temporal resolution was one hour in these domains. The temperature, pressure, relative humidity and height values in the third domain (i.e., the $3 \mathrm{~km}$ resolution) were interpolated for providing a voxel grid with a $1^{\prime}$ interval at both latitudinal and longitudinal directions, and a vertical interval the same as that of these domains. (a)

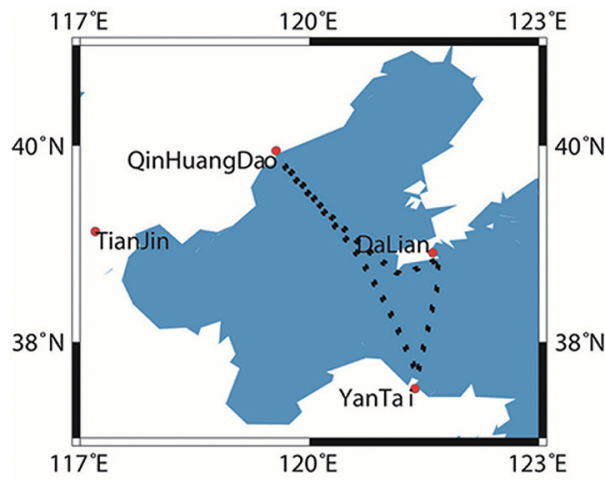

(b)

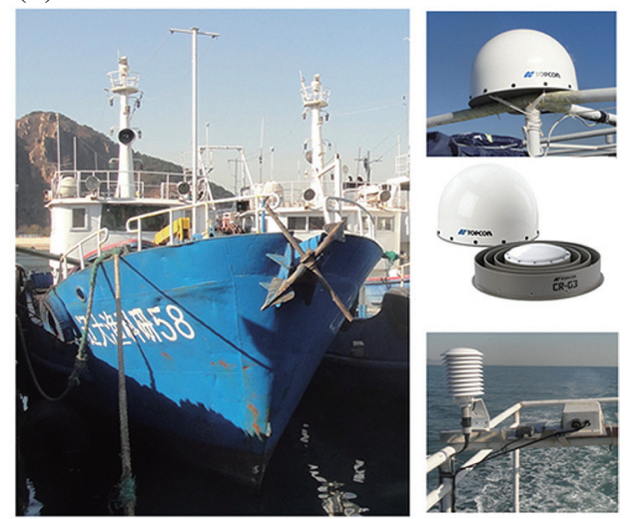

Fig. 1. (a) A schematic map showing the sailing route of the experimental ship and (b) the images of the ship, GPS receiver antenna and meteorological sensors used for the data collection. (Color online only) 


\section{AWV ESTIMATES}

Two types of PWV and SWV estimates are compared in this study: GPS-PWV and GPS-SWV derived from the ship-borne GPS observations, MM5-PWV and MM5-SWV integrated by the MM5 data.

\subsection{GPS-PWV and GPS-SWV}

A powerful PPP-based processing engine developed with the sequential least squares estimation and a forward and reverse filter strategy (Fan et al. 2010) was used to process all ship-borne GPS measurements on an epoch-byepoch basis in the kinematic mode. The precise IGS (International GNSS Service) rapid orbit (at 15-min intervals) and satellite clocks (at 5-min intervals) were interpolated to 1 -sec intervals aligned with the GPS data sampling rate. The global mapping function (GMF) model (Boehm et al. 2006) was used to map the GPS zenith delay into the slant-path along the signal transmission. The tropospheric zenith wet delay (ZWD) and horizontal gradient parameters $\left(\mathrm{G}_{\mathrm{N}}\right.$ and $\mathrm{G}_{\mathrm{E}}$ ) were estimated along with the receiver coordinates. The random walk processes with an appropriate noise constraint for these three parameters were assumed, which are discussed in the section 4 in this paper. An elevation cut-off of $10^{\circ}$ was applied for the GPS data processing. The $1 / \cos (e)$ weighting scheme was used to determine the weight of GPS measurements in the estimation system. For obtaining good estimation results, a forward and reverse filter strategy was utilized in the data processing for the beginning part (about $30 \mathrm{~min}$ ) of the data series where GPS carrier phase ambiguity would usually not converge.

Based on the ZWD estimates derived from the aforementioned GPS data processing and a temperature-dependent conversion factor $\Pi$, PWV can be calculated by (Bevis et al. 1992, 1994):

$\mathrm{PWV}=\Pi \times \mathrm{ZWD}$

$\Pi=\frac{10^{6}}{\rho R_{V}\left(k_{3} / T_{m}+k_{2}-m k_{1}\right)}$

where $\rho$ is the density of liquid water $\left(\mathrm{kg} \mathrm{m}^{-3}\right) ; R_{V}$ is the specific gas constant for water vapor; $k_{1}, k_{2}$, and $k_{3}$ are the three empirically derived refraction constants; $m$ is the ratio of the molar masses of water vapor and dry air; $T_{m}$ is the weighted mean temperature of the atmosphere $(\mathrm{K})$ and obtained by the empirical model, e.g., (Bevis et al. 1992), using the surface air temperature observations from the meteorology sensor on the ship in this investigation. The effect of different $T_{m}$ models on the AWV retrieval was discussed in the section 4.

While for obtaining the SWV value, the first step was to calculate the slant-path wet delay (SWD) using the ZWD,
$\mathrm{G}_{\mathrm{N}}$, and $\mathrm{G}_{\mathrm{E}}$ estimates together with the post-fit residual $v$ to each measurement from the GPS PPP algorithm (Flores et al. 2000):

$\mathrm{SWD}=M_{\text {wet }}(e) \mathrm{ZWD}+M_{\Delta}(e)\left(\mathrm{G}_{\mathrm{N}} \cos \phi+\mathrm{G}_{\mathrm{E}} \sin \phi\right)+v$

The second step was to use the conversion factor $\Pi$ to convert the SWD into SWV with the method proposed by (Bevis et al. 1994):

$\mathrm{SWV}=\Pi \times \mathrm{SWD}$

\subsection{MM5-PWV and MM5-SWV}

In order to obtain the MM5-derived PWV and SWV values for GPS results validation, the tropospheric wet delay (TWD) of the satellite signal needs to be simulated first. The numerical integral of the atmospheric wet refractivity along a GPS signal path (Bevis et al. 1992) were used to calculate the TWD:

$\mathrm{TWD}=10^{-6} \int_{s} N_{w}(s) d s$

where $N_{w}$ is the wet refractivity of the atmosphere and it can be obtained using the empirical Smith and Weintraub model (Smith and Weintraub 1953); and $s$ is the GPS signal ray path.

The ZWD and SWD can be simulated by integrating along the zenith and slant path in Eq. (5) respectively. The MM5-derived ZWD and SWD were then converted into PWV and SWV using Eqs. (1) and (4), respectively, which are the so-called MM5-PWV and MM5-SWV.

For the above numerical integral of wet refractivity, in practice, it commonly uses the sum of the TWDs in all those voxels that the GPS signal passes through. The TWD in each voxel is calculated by the wet refractivity of the voxel multiplied with the GPS signal path length in the voxel. It is very difficult to calculate the GPS signal path length in a voxel from the original MM5 grid, which uses isobaric surfaces (curves) to determine the vertical layers. The height planes that were closest to the mean heights of the MM5 isobaric surfaces were used to re-determine the vertical layers. More specifically, a 100-m interval was adopted for heights below $0.8 \mathrm{~km}$, a $200-\mathrm{m}$ interval for heights between 0.8 and $2 \mathrm{~km}$, a 500-m interval for heights between 2 and $5 \mathrm{~km}$, and a 1000 -m interval for heights above $5 \mathrm{~km}$.

\section{DISCUSSIONS}

In order to obtain good GPS AWV estimates some parameter settings and empirical models in the PPP engine should be adjusted along with the various observation 
conditions, especially the kinematic observation in open sea areas. The effects of atmospheric weighted mean temperature model and ZWD constraint on the GPS AWV estimation are discussed.

\subsection{Empirical Model of Atmospheric Weighted Mean Temperature}

If the relative error in $T_{m}$ exceeds about $1-2 \%$, then the relative error in the proportionality factor $\Pi$ closely approximates the relative error in $T_{m}$ (Bevis et al. 1994). The factor $\Pi$ error is dominated mainly by the $T_{m}$ error. It is very necessary to select a proper $T_{m}$ model for retrieving AWV from the atmospheric wet delay. Several models including Bevis et al. (1992), Mendes et al. (2000), Schueler et al. (2001), and Zhang et al. (2010) were used in this study to validate the $T_{m}$ model effect on the AWV retrievals. Table 1 shows the statistics for the differences between GPS AWV derived from different $T_{m}$ models and that retrieved from MM5 data. It is obvious that both PWV and SWV results from these four models are very similar. The accuracies (RMS) of GPSPWV and GPS-SWV all reach 1.5 and $3.9 \mathrm{~mm}$, respectively, compared against the corresponding MM5 AWV results.

\subsection{ZWD Constraint}

A random walk process can reasonably well describe the wet delay variability in GPS data analyses (Herring et al. 1990). Different constraints for the atmospheric parameters may be set up with the values listed by Gradinarsky et al. (2000). The range of $0.2-15 \mathrm{~mm} \sqrt{\mathrm{h}}^{-1}$ was set for the ZWD constraint and the same $T_{m}$ model (Zhang et al. 2010) was used for validation according to the motion state of ship-borne GPS receiver and the spatio-temporal variability of AWV during the Bohai Sea experiment. The GPS-PWV and GPS-SWV results estimated from different ZWD constraints were compared against the MM5-PWV and MM5SWV, respectively. The statistics for these differences are listed in Table 2.

From Table 2 it can be seen that the excessively tight ZWD constraint (higher than $2 \mathrm{~mm}$ ) in this study could greatly affect the AWV estimate accuracy, which results in large spikes. The $0.2-1 \mathrm{~mm} \sqrt{\mathrm{h}}^{-1}$ range for more loose ZWD constraint was recommended for this research. This may be related to the low dynamics of the ship-borne GPS receiver and the gentle spatio-temporal variation along the ship route.

\section{RESULTS}

According to the above discussions the $T_{m}$ model (Zhang et al.2010) and ZWD constraint of $1 \mathrm{~mm} \sqrt{\mathrm{h}}^{-1}$ were set up in our PPP engine for the ship-borne GPS AWV estimation. Then both PWV and SWV results were compared with those derived from the MM5 data.

Table 1. Statistics for the differences between GPS AWV derived from different $T_{m}$ model and that retrieved from MM5 data.

\begin{tabular}{c|cccc|cccc}
\hline \multirow{2}{*}{$\boldsymbol{T}_{\boldsymbol{m}}$ model } & \multicolumn{4}{|c|}{ PWV $(\mathbf{m m})$} & \multicolumn{4}{c}{ SWV $(\mathbf{m m})$} \\
\cline { 2 - 9 } & Max. & Min. & Mean & RMS & Max. & Min. & Mean & RMS \\
\hline Bevis & 2.7 & -3.6 & 0.3 & 1.5 & 14.6 & -18.5 & -0.5 & 3.9 \\
Mendes & 2.6 & -3.6 & 0.3 & 1.5 & 14.5 & -18.6 & -0.5 & 3.9 \\
Schueler & 2.6 & -3.7 & 0.2 & 1.5 & 13.8 & -18.9 & -0.7 & 3.9 \\
Zhang & 2.5 & -3.7 & 0.2 & 1.5 & 13.7 & -19.0 & -0.7 & 3.9 \\
\hline
\end{tabular}

Table 2. Statistics for the differences between GPS AWV estimated from different ZWD constraint for random walk process and corresponding MM5 results.

\begin{tabular}{c|rccc|cccc}
\hline \multirow{2}{*}{$\begin{array}{c}\text { ZWD Constraint } \\
\left(\mathbf{m m} \sqrt{\mathbf{h}}^{-1}\right)\end{array}$} & \multicolumn{4}{|c|}{ PWV $(\mathbf{m m})$} & \multicolumn{5}{c}{ SWV (mm) } \\
\cline { 2 - 9 } & Max. & Min. & Mean & RMS & Max. & Min. & Mean & RMS \\
\hline 0.2 & 4.8 & -3.1 & 0.4 & 1.5 & 16.5 & -16.3 & -0.3 & 3.6 \\
0.5 & 3.3 & -3.4 & 0.3 & 1.4 & 11.7 & -19.3 & -0.6 & 3.6 \\
0.8 & 2.4 & -3.6 & 0.2 & 1.4 & 12.6 & -19.4 & -0.7 & 3.8 \\
1 & 2.5 & -3.7 & 0.2 & 1.5 & 13.7 & -19.0 & -0.7 & 3.9 \\
2 & 3.5 & -4.0 & 0.3 & 1.8 & 18.6 & -18.8 & -0.5 & 4.4 \\
5 & 17.4 & -4.3 & 0.6 & 3.3 & 43.1 & -19.8 & 0.4 & 6.6 \\
10 & 27.3 & -4.3 & 0.9 & 4.7 & 71.0 & -20.1 & 0.4 & 8.7 \\
15 & 30.2 & -4.3 & 1.0 & 5.2 & 79.3 & -20.1 & 0.5 & 9.4 \\
\hline
\end{tabular}




\subsection{PWV Comparison}

A comparison of the GPS-PWV and MM5-PWV time series for the 3-day experimental period are shown in Fig. 2a. It should be noted that this figure only shows those epochs whose PWV results were provided at a one-hour interval in the MM5 data. From these comparisons of both PWVs, we can see the experiment is somehow under a low water vapor environment. The scatter diagram of both PWVs is illustrated in Fig. 2b. The GPS-PWV agrees well with the MM5-PWV. Taking the MM5-PWV as a reference, the bias and RMS of the differences between the two PWVs were 0.2 and $1.5 \mathrm{~mm}$ respectively. The accuracy achieved is similar with the ground-based GPS results reported in earlier studies (Guerova et al. 2003; Gendt et al. 2004) under a stationary environment.

\subsection{SWV Comparison}

The GPS-SWV and MM5-SWV time series from satellite PRN (Pseudo Random Noise) 2, 15, 28, and 30 are plotted in Fig. 3 to show the differences between the two SWVs and the variations in the SWV. Figure 4 shows the scatter diagram of both SWVs from all satellites observed. The GPS-SWV is also in a good agreement with the MM5-SWV. Taking the MM5-SWV as a truth, the bias and RMS of the differences between the two SWVs were -0.7 and $3.9 \mathrm{~mm}$. This indicates that the GPS-SWV results accuracy over the Bohai Sea is again similar to what can be achieved from the ground-based GPS-SWV presented in (Bender et al. 2008).

Figure 5 shows the variation in GPS-SWV and MM5SWV differences with regard to the satellite elevation angle. It was found that the higher the elevation, the smaller the difference of both SWVs. From Tables 1 and 2 we can see that the maximum (absolute) values in the differences of the two SWVs were significantly larger than their PWV counterparts and these maximum differences occurred when the elevation was the lowest (see Fig. 5). The increase in the differences between the two sets of SWVs is likely to be due to the increase in the GPS observation errors caused by the atmospheric delay, multipath effect and measurement noise when the satellite elevation angle decreases. Therefore, it is very important to adopt an appropriate elevation mask for optimal GPS-derived SWV over the sea region.

\section{CONCLUSIONS}

Both PWV and SWV were estimated from a single GPS receiver aboard a lightweight ship in the Bohai Sea, China. This is the first of its kind experiment conducted by the Chinese Authority to investigate the potential use of GPS-based AWV in the Bohai Sea. The GPS TWDs and receiver coordinates were estimated using the advanced GPS PPP algorithm and the software package developed by the authors. The GPS-derived PWV and SWV were validated by comparing against those obtained from the MM5 model. The RMS and bias values of the differences between both PWVs were 1.5 and $0.2 \mathrm{~mm}$, respectively; and the corresponding SWV results were 3.9 and $-0.7 \mathrm{~mm}$, respectively. The good agreement between the GPS and MM5 results indicates that high accuracy AWV results can be obtained from ship-borne GPS measurements in a relatively dynamic environment. These ship-borne GPS AWV results are also comparable with those achieved from the ground-based GPS system.

The Bohai Sea is surrounded by land on three sides. This unique geographical characteristic provides an inherent advantage for 3D water vapor tomography over the region, since GPS-SWVs retrieved from both ship-borne and ground-based GPS measurements can be used. Our future work will focus on using GPS-SWVs retrieved from both ship-borne and buoy-based GPS measurements together with offshore ground-based GPS measurements to develop a 3D water vapor tomographic system for the Bohai Sea region.
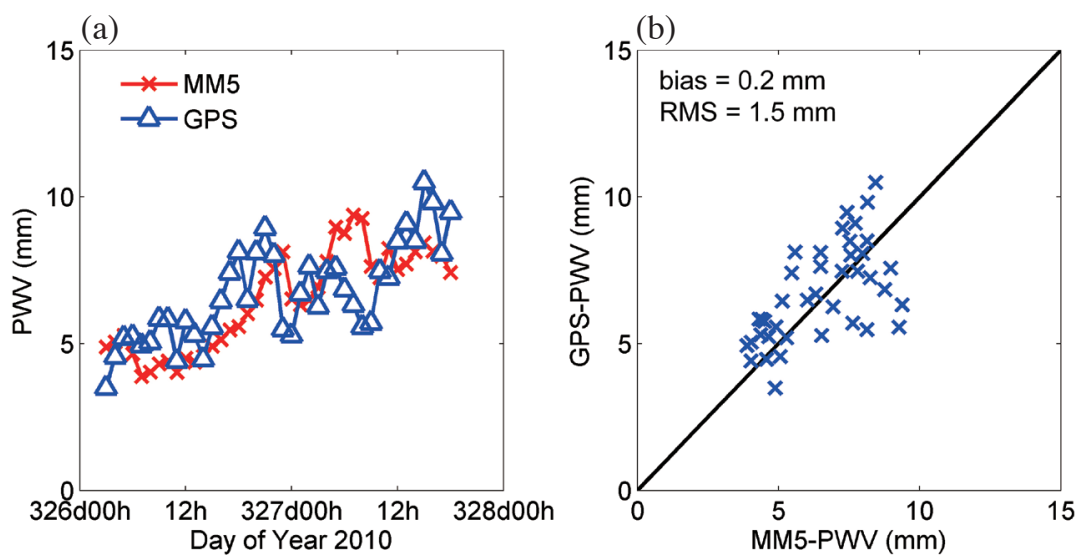

Fig. 2. (a) A comparison of the GPS-PWV and MM5-PWV time series and (b) a scatter diagram of the GPS-PWV and MM5-PWV results. (Color online only) 

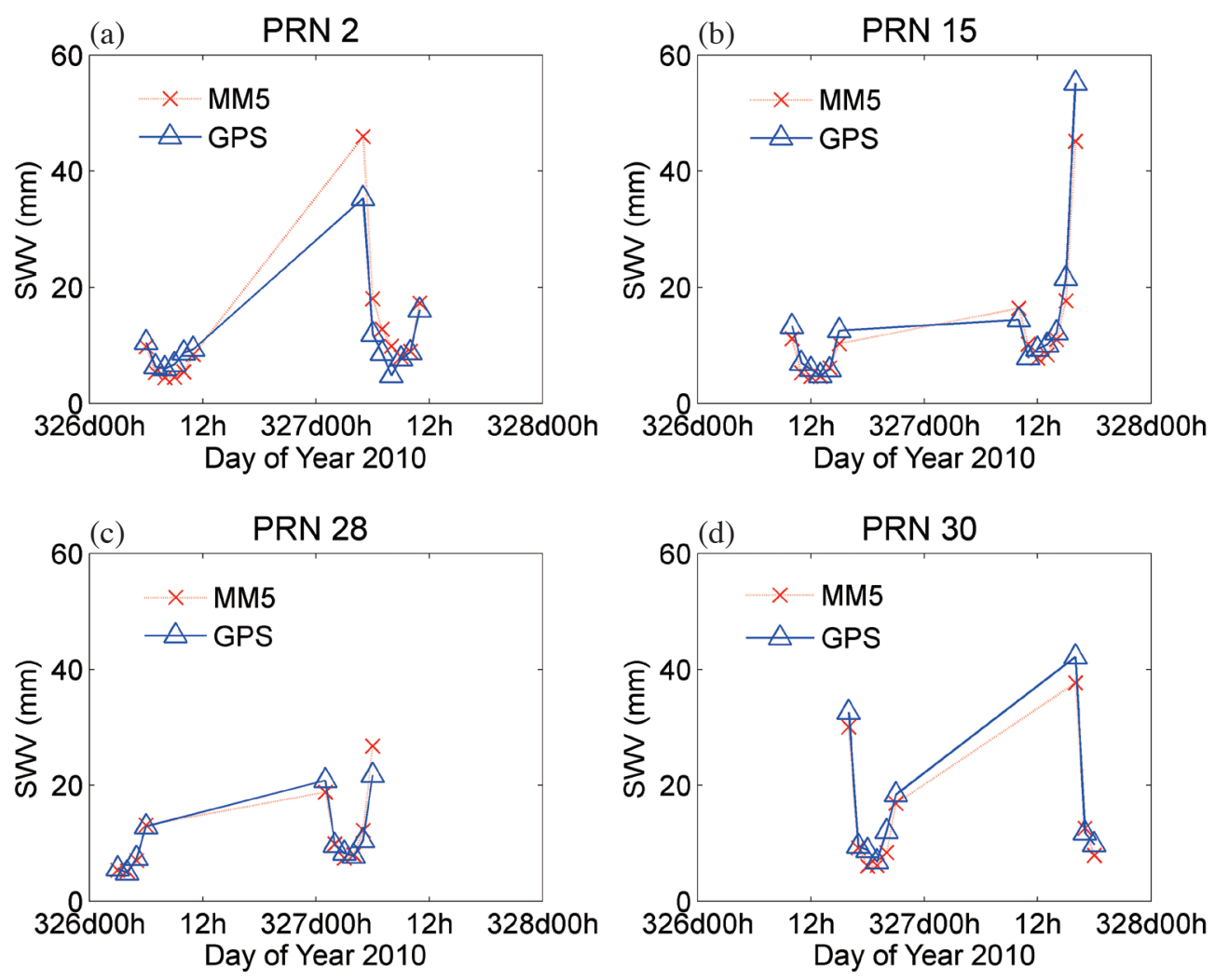

Fig. 3. GPS-SWV and MM5-SWV time series from satellite PRN 2, 15, 28, and 30, indicating both the differences between the two sets of SWVs and the variation in SWV with time. (Color online only)

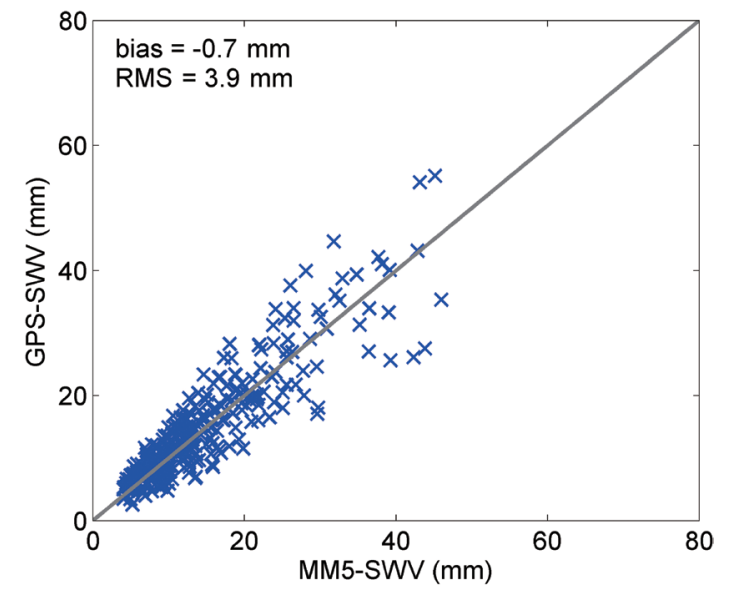

Fig. 4. A scatter diagram of the GPS-SWV and MM5-SWV from all satellites observed. (Color online only)

It is expected that the high spatial-temporal resolution tropospheric humidity fields will be significant for meteorological applications and climate studies for the region.

Acknowledgments We are thankful for funding from the China Scholarship Council. This study was supported by the National Natural Science Foundation of China (grant no.

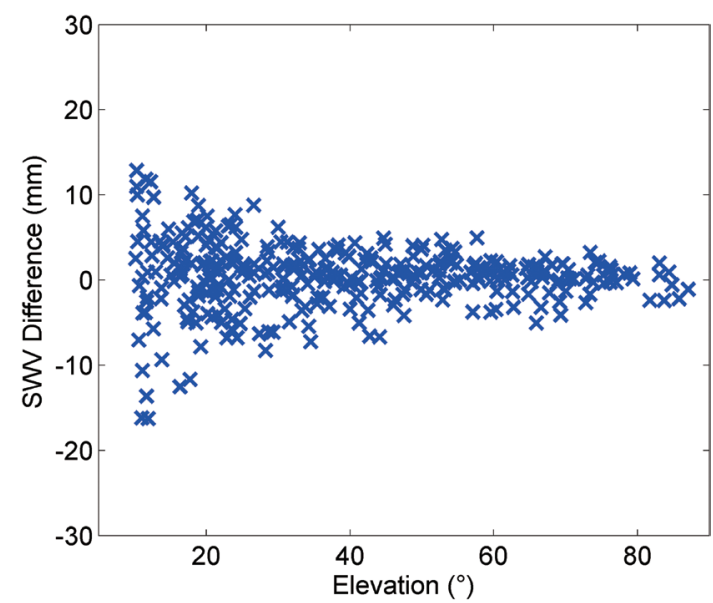

Fig. 5. The variation in the differences between the GPS-SWV and MM5-SWV with regard to the satellite elevation angle. (Color online only)

41274011, 41374044, and 41374008). GNSS meteorology research at the RMIT SPACE Research Centre is primarily supported through the following projects: the Natural Disaster Resilience Grants Scheme (NDRG) of Victoria, the Australian Space Research Program (ASRP) project, and the Australian Research Council (ARC) Linkage (LP0883288) project. 


\section{REFERENCES}

Bender, M., G. Dick, J. Wickert, T. Schmidt, S. Song, G. Gendt, M. Ge, and M. Rothacher, 2008: Validation of GPS slant delays using water vapour radiometers and weather models. Meteorol. Z., 17, 807-812, doi: 10.1127/0941-2948/2008/0341. [Link]

Bevis, M., S. Businger, T. A. Herring, C. Rocken, R. A. Anthes, and R. H. Ware, 1992: GPS meteorology: Remote sensing of atmospheric water vapor using the global positioning system.J.Geophys. Res., 97, 15787-15801, doi: 10.1029/92JD01517. [Link]

Bevis, M., S. Businger, S. Chiswell, T. A. Herring, R. A. Anthes, C. Rocken, and R. H. Ware, 1994: GPS meteorology: Mapping zenith wet delays onto precipitable water. J. Appl. Meteorol., 33, 379-386, doi: 10.1175/1520-045 0(1994)033<0379:GMMZWD>2.0.CO;2. [Link]

Boehm, J., A. Niell, P. Tregoning, and H. Schuh, 2006: Global Mapping Function (GMF): A new empirical mapping function based on numerical weather model data. Geophys. Res. Lett., 33, L07304, doi: 10.1029/2005GL025546. [Link]

Boniface, K., C. Champollion, J. Chery, V. Ducrocq, C. Rocken, E. Doerflinger, and P. Collard, 2012: Potential of shipborne GPS atmospheric delay data for prediction of Mediterranean intense weather events. Atmos. Sci. Lett., 13, 250-256, doi: 10.1002/asl.391. [Link]

Chadwell, C. D. and Y. Bock, 2001: Direct estimation of absolute precipitable water in oceanic regions by GPS tracking of a coastal buoy. Geophys. Res. Lett., 28, 3701-3704, doi: 10.1029/2001GL013280. [Link]

Fan, S., Y. Liu, C. Xu, J. Guo, and Z. Wang, 2010: GPS kinematic Precise Point Positioning based on sequential least squares estimation. $201018^{\text {th }}$ International Conference on Geoinformatics, IEEE, 1-5, doi: 10.1109/ GEOINFORMATICS.2010.5567623. [Link]

Flores, A., G. Ruffini, and A. Rius, 2000: 4D tropospheric tomography using GPS slant wet delays. Ann. Geophys., 18, 223-234, doi: 10.1007/s00585-000-0223-7. [Link]

Fujita, M.,F. Kimura, K. Yoneyama, and M. Yoshizaki, 2008: Verification of precipitable water vapor estimated from shipborne GPS measurements. Geophys. Res. Lett., 35, L13803, doi: 10.1029/2008GL033764. [Link]

Gao, B. C. and Y. J. Kaufman, 2003: Water vapor retrievals using Moderate Resolution Imaging Spectroradiometer (MODIS) near-infrared channels. J. Geophys. Res., 108, doi: 10.1029/2002JD003023. [Link]

Gendt, G., G. Dick, C. Reigber, M. Tomassini, Y. Liu, and M. Ramatschi, 2004: Near real time GPS water vapor monitoring for numerical weather prediction in Germany. J. Meteorol. Soc. Jpn., 82, 361-370, doi: 10.2151/ jmsj.2004.361. [Link]

Gradinarsky, L. P., R. Haas, G. Elgered, and J. M. Johans- son, 2000: Wet path delay and delay gradients inferred from microwave radiometer, GPS and VLBI observations. Earth Planets Space, 52, 695-698, doi: 10.1186/ BF03352266. [Link]

Grell, G. A., J. Dudhia, and D. R. Stauffer, 1994: A description of the fifth-generation Penn State/NCAR mesoscale model (MM5). NCAR Technical Note NCAR/ TN-398+STR, doi: 10.5065/D60Z716B. [Link]

Guerova, G., E. Brockmann, J. Quiby, F. Schubiger, and C. Matzler, 2003: Validation of NWP mesoscale models with Swiss GPS network AGNES. J. Appl. Meteorol., 42, 141-150, doi: 10.1175/1520-0450(2003)042<0141:VONMMW>2.0.CO;2. [Link]

Herring, T. A., J. L. Davis, and I. I. Shapiro, 1990: Geodesy by radio interferometry: The application of Kalman filtering to the analysis of very long baseline interferometry data. J. Geophys. Res., 95, 12561-12581, doi: 10.1029/JB095iB08p12561. [Link]

Jackson, D. L. and G. L. Stephens, 1995: A study of SSM/IDerived columnar water vapor over the global oceans. J. Climate, 8, 2025-2038, doi: 10.1175/1520-0442(1995)008<2025:ASOSDC>2.0.CO;2. [Link]

Kain, J. S., 2004: The Kain-Fritsch convective parameterization: An update. J. Appl. Meteorol., 43, 170-181, doi: 10.1175/1520-0450(2004)043<0170:TKCPAU >2 .0.CO;2. [Link]

Kealy, J., J. Foster, and S. Businger, 2012: GPS meteorology: An investigation of ocean-based precipitable water estimates. J. Geophys. Res., 117, D17303, doi: 10.1029/2011JD017422. [Link]

Li, Z., J. P. Muller, and P. Cross, 2003: Comparison of precipitable water vapor derived from radiosonde, GPS, and Moderate-Resolution Imaging Spectroradiometer measurements. J. Geophys. Res., 108, doi: 10.1029/2003JD003372. [Link]

Memmo, A., E. Fionda, T. Paolucci, D. Cimini, R. Ferretti, S. Bonafoni, and P. Ciotti, 2005: Comparison of MM5 integrated water vapor with microwave radiometer, GPS, and radiosonde measurements. IEEE Trans. Geosci. Remote Sensing, 43, 1050-1058, doi: 10.1109/ TGRS.2004.841488. [Link]

Mendes, V. B., G. Prates, L. Santos, and R. B. Langley, 2000: An evaluation of the accuracy of models for the determination of the weighted mean temperature of the atmosphere. Proceedings of the 2000 National Technical Meeting of the Institute of Navigation, 433-438.

Posada, R., E. García-Ortega, J. L. Sánchez, and L. López, 2013: Verification of the MM5 model using radiosonde data from Madrid-Barajas Airport. Atmos. Res., 122, 174-182, doi: 10.1016/j.atmosres.2012.10.018. [Link]

Rocken, C., J. Johnson, T. Van Hove, and T. Iwabuchi, 2005: Atmospheric water vapor and geoid measurements in the open ocean with GPS. Geophys. Res. Lett., 32, L12813, doi: 10.1029/2005GL022573. [Link] 
Rohm, W., Y. Yuan, B. Biadeglgne, K. Zhang, and J. Le Marshall, 2014: Ground-based GNSS ZTD/IWV estimation system for numerical weather prediction in challenging weather conditions. Atmos. Res., 138, 414426, doi: 10.1016/j.atmosres.2013.11.026. [Link]

Schueler, T., A. Pósfay, G. W. Hein, and R. Biberger, 2001: A global analysis of the mean atmospheric temperature for GPS water vapor estimation. Proceedings of the $14^{\text {th }}$ International Technical Meeting of the Satellite Division of the Institute of Navigation (ION GPS 2001), Salt Lake City, UT, September 2001, 2476-2489.

Smith, E. K. and S. Weintraub, 1953: The constants in the equation for atmospheric refractive index at radio frequencies. Proc. IRE, 41, 1035-1037, doi: 10.1109/JRPROC.1953.274297. [Link]

Stephens, G. L., 1984: The parameterization of radiation for numerical weather prediction and climate models. Mon. Weather Rev., 112, 826-867, doi: 10.1175/15200493(1984)112<0826:TPORFN>2.0.CO;2. [Link]

Yeh, T. K., J. S. Hong, C. S. Wang, T. Y. Hsiao, and C. T. Fong, 2014: Applying the water vapor radiometer to verify the precipitable water vapor measured by GPS. Terr. Atmos. Ocean. Sci., 25, 189-201, doi: 10.3319/ TAO.2013.10.14.01(A). [Link]

Yoneyama, K., M. Fujita, N. Sato, M. Fujiwara, Y. Inai, and F. Hasebe, 2008: Correction for radiation dry bias found in RS92 radiosonde data during the MISMO field experiment. SOLA, 4, 13-16, doi: 10.2151/ sola.2008-004. [Link]

Yuan, Y., K. Zhang, W. Rohm, S. Choy, R. Norman, and C. S.Wang, 2014: Real-time retrieval of precipitable water vapor from GPS precise point positioning. J. Geophys. Res., 119, 10044-10057, doi: 10.1002/2014JD021486. [Link]

Zhang, H., Y. Liu, X. Zhou, Q. Tang, and J. Ding, 2010: Weighted mean temperature in Bohai. J. Geomatics, 4, 1-2.

Zumberge, J. F., M. B. Heflin, D. C. Jefferson, M. M. Watkins, and F. H. Webb, 1997: Precise point positioning for the efficient and robust analysis of GPS data from large networks. J. Geophys. Res., 102, 5005-5017, doi: 10.1029/96JB03860. [Link] 